\title{
UNCLASSIFIED
}

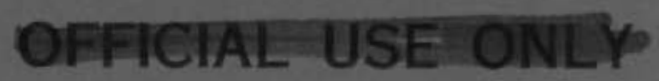

\section{PACIFIC NORTHWEST LABORATORY MONTHLY ACTIVITIES REPORT FOR JUNE 1967}

DEVELOPMENT REPORT
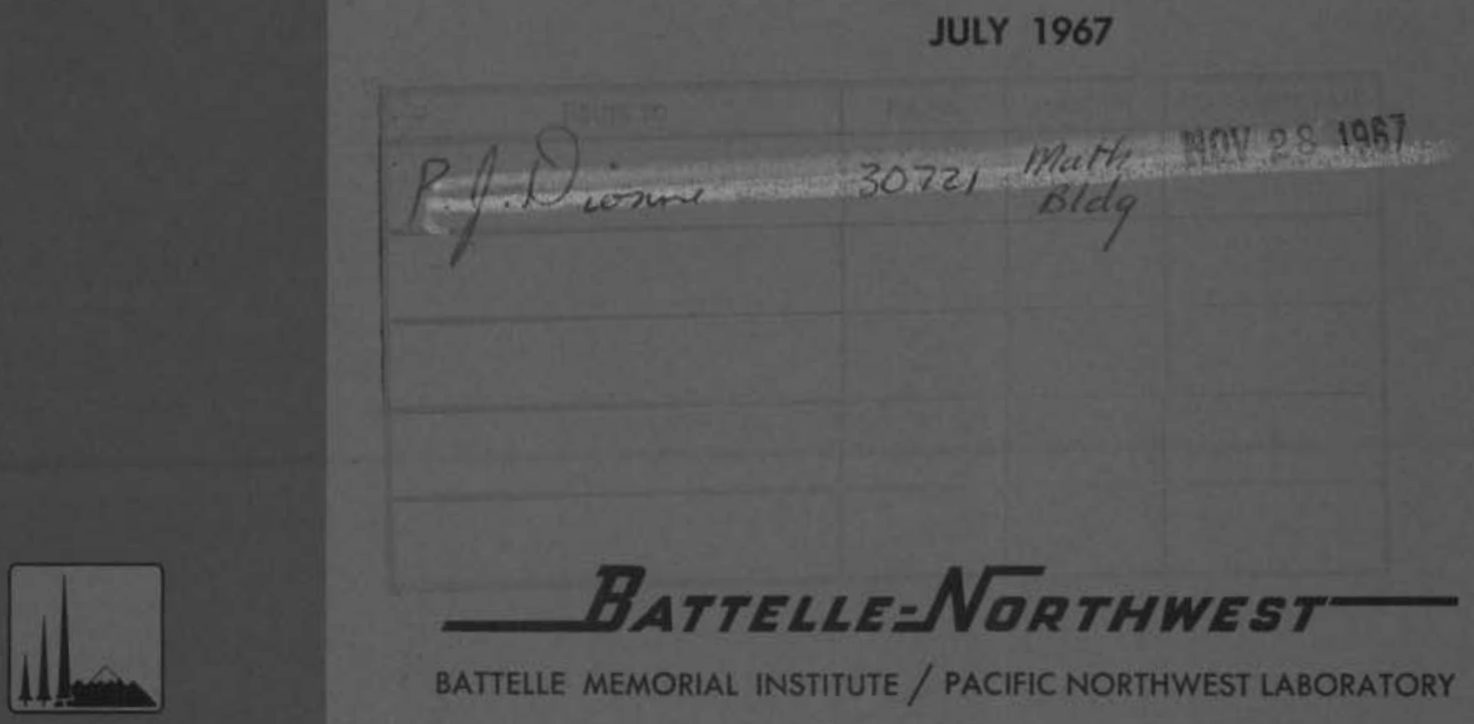

BATTELLE MEMORIAL INSTITUTE / PACIFIC NORTHWEST LABORATORY 

PATEN7

This documenteney, since it is transmitted in advance of pcitent cleorance, is made available in confidence solely for use in performance of work under contracts with the U.S. Atomic Energy Cornmission. This document is not to be published nor its contents otherwise disseminated or used for purposes other than specified above before potehtapproval for such release or use has been secured, upon request, from the Chief, Chicago Patent Group, U, 5. Atomic Energy Commission. 9800 So. Cass Ave. Argonne, llitinois.

\title{
PRELIMINARY REPORT
}

This repoty contains information of a preliminary nature prepared in the course of work under Atomic Energr Commission Contract AT(45-1)-1830. This information is subject to terrection or modification upar the collection and avaluation of additional data.

\section{LEGAL NOTICE}

This report was prepared as an occount of Government sponsored work. Neither the United States, nor the Commission, nor any person acting on behalf of the Commission.

A. Makes any warranty or cepresentation, expressed or implied, with respect to the accuracy, com. pleteness, or usefulness of the information contained in this report, or that the use of any information, apparatus, methad, or process disclosed in this report may not infringe privotely owned rights; or

B. Assumes any liabilities with respect to the use of, or for damages resulting from the use af any information, apparatus, method, or process disclosed in this report.

As used in the above, "person acting on behalf of the Commission" includes any employee or contractor of the Commission, or employee of such contractor, to the extent that such employee or contractor of the Commissiow, or employee of such contracior prepares, disseminates, or provides access to, any information pursuant to his employment or contract with the Commission, or his employment with such contractor.

\author{
PACIFIC NORTHWEST LABORATORY \\ RICHLAND, WASHINGTON \\ operated by \\ BATTELLE MEMORIAL INSTITUTE \\ for the \\ UNITED STATES ATOMIC ENERGY COMMISSION UNDER CONTRACT AT(45-1)-1830
}

PRINTED BY/FOR THE U,S, ATOMIC ENERGY COMMISSION 
UNCLASSIEED

BNWL -497

UC- 48

Biology and Medicine

(Special Distribution)

PACIFIC NORTHWEST LABORATORY

MONTHLY ACTIVITIES REPORT

JUNE 1967

Division

of

Biology and Medicine

Programs

by the

Staff of Battelle-Northwest

S. I. Fawcett, Director

July, 1967

PACIFIC NORTHWEST LABORATORY

RICHLAND, WASHINGTON 
PACIFIC NORTHWEST LABORATORY

MONTHLY ACTIVITIES REPORT

JUNE 1967

AEC DIVISION OF BIOLOGY AND MEDICINE PROGRAMS - R. S. PAUL

\section{RADIATION EFFECTS - GENERAL}

Mechanism and Treatment of Gastrointestinal Radiation Effects - M. F. Sullivan

Preliminary results from rats with an external lymphatic fistula suggest that protein mobilization into the lymph is increased threefold by exposure of the abdominal region to radiation. Further studies to confirm this effect and to demonstrate the influence of pancreatic secretion on the irradiated bowel are in progress.

Both in vitro and in vivo studies are in progress, the purpose of which is to demonstrate the role of bile on fluid and electrolyte transport in the irradiated gut. Recent results have indicated that, in the absence of bile, function of the irradiated colon is superior to that of non-fistula irradiated rats.

It was shown, in vivo, that the presence of fluid in the bowel, as occurs in the case of the irradiated intestine, attracts sodium from the circulating blood. For example, in 30 minutes $1.5 \%$ of an intravenous-administered dose of ${ }^{22} \mathrm{Na}$ appeared in the normal small intestine, 6\% in the irradiated (1250 R) intestine, and $10 \%$ in either the normal or irradiated intestine injected with $10 \mathrm{ml}$ of phosphate buffer or water prior to $22 \mathrm{Na}$ injection.

It is now clear from our studies on the function of the enteric coat in rats that whole-body exposure to $\mathrm{x}$-irradiation of $1000 \mathrm{R}$ induces an immediate response in fully mature and differentiating intestinal absorptive cells. This response is an alteration in the functioning of the Golgi complex; it is not detectable morphologically, but is readily apparent when 
appropriate cytological methods are used. One of the altered functions of the Golgi complex includes increased sulfation of acid mucopolysaccaride (AMPS). AMPS synthesized by the Golgi complex is a precursor material of the enteric surface coat.

From the results that we have obtained and from those reported in the literature, the enteric surface coat can now be described as two separate entities; based on morphological as well as functional criteria. The first layer of the surface coat appears to be consistently present in all species. This layer has been termed the knobby layer and resides in the region immediately external to the membrane of the microvillus. Certain enzymes involved in terminal carbohydrate digestion reside in this knobby layer. The second layer of the surface coat is a filamentous layer that is largely AMPS. This filamentous layer exhibits species variations in that it is present in man, cat, and bat. In unirradiated rats, the filamentous layer is absent; however, it can be induced by various stimuli, including $\mathrm{x}$-irradiation. The function of the filamentous layer is still speculative. It is possible that the AMPS layer on the cell surface might provide an exchange medium for the absorptive cells that are involved in the transport of water and ions. In view of the differences in the transport of water and ions in the rat after $\mathrm{x}$-irradiation, this possibility is presently being investigated.

\section{TOXICITY OF RADIOELEMENTS}

Factors Affecting the Toxicity and Metabolism of Radionuclides - M. F. Sullivan

Rats injected with $239 \mathrm{Pu}$ at birth, weaning time, or as young adults were examined for effects 3 months later. Those injected at birth with 60 or $90 \mu \mathrm{Ci} / \mathrm{kg}$ showed tumor involvement of the liver. Weanlings exhibited deformations and extreme brittleness of their leg bones. Spontaneous fractures with subsequent callus formation at the fracture were seen in the femurs. In those rats given $\mathrm{Pu}$ as the colloid, spleen size was reduced while, in contrast, atrophy and lymphatic hyperplasia occurred in the spleen after injection of the citrate. The liver and bone involvement noted in these studies after $\mathrm{Pu}$ injection was not apparent before 90 days. The rapid onset of liver tumors was quite unexpected. 
Factors Affecting the Toxicity and Metabolism of Radionuclides in Aquatic Organisms - R. E. Nakatani

Four lots of chinook salmon fry were transferred to aquaria in preparation for evaluation of effects of acute gamma radiation $\left({ }^{60} \mathrm{Co}\right)$ on these animals. A radiation exposure tank was constructed and preliminary dosimetry tests were made in this tank using IiF powder dosimeters.

The freshwater mussels (Margaritifera margaritifera) collected from the ozette River that possessed large edematous lesions have been extensively studied histologically in an attempt to ascertain their possible cause. The lesions appear to be a response to injury, but no definite causative agent has been observed. In several of the diseased animals, unusual cells have been observed containing multiple inclusions with clear "halos" around the inclusions. These bodies are not bacteria. They may be a fungus that has been phagocytosed by host cells. However, the entire cell, including the inclusions, superficially resembles an amoeba (Valkampia) which is known to infect oysters.

\section{Effects of Radiostrontium in Miniature Swine - W. J. Clarke}

Two additional cases of myelogenous leukemia were diagnosed this month in 6-year-old $125 \mu \mathrm{Ci} /$ ay swine. This brings the total number of cases of myeloproliferative and lymphoproliferative disorders occurring in this study to 52 .

Generation cycle analysis of curves representing percent tritiated thymidine labeling of unclassified immature cells and rubricyte mitoses in control swine marrow indicates that times for $G_{2}$, mitosis, and $D N A S$ phases are comparable to those of man. However, the time for $G_{1}$ is shorter in swine than in man. Similar analysis was attempted for myelocyte mitoses but meaningful results were not obtained. A possible cause for this might be the presence of both an immature and a mature myelocyte population with different generation cycle rates. Material from a second animal is being analyzed with this possibility in mind.

The studies reported in May concerning the lymphoid stimulatory effect of lympholeukemia filtrate was repeated again using pig spleen culture with similar results.

DBA/2 mice carrying P388F lymphoid leukemia cells have been acquired. Cells from one animal have been harvested and started 
in a culture system. These particular cells are a genetically stable line that grow in suspension culture with a doubling time of less than 24 hours. It is planned to inoculate this line with the same lympholeukemia filtrate previously used to see if the stimulatory effect crosses species lines. To further characterize this filtrate, a supernatant from a 110,000 G centrifugate will be tested in a like manner.

Concentrated effort is being started along several lines for the study of strontium-90 induced pig leukemia cells to determine if a specific antigen may be associated with these cells. This antigen could be altered cellular components or activated latent subcellular particles. A number of primary and stable cell lines are being started for inoculation and blind passage of pig leukemia filtrates. These cover a wide range of species, and will provide the opportunity for uncovering latent or masked viruses. The cells will be examined microscopically for cytopathic effect following inoculation, and also biochemically for enzyme activity related to nucleic acid metabolism. In addition, the cultured cells will be examined by direct fluorescent antibody staining technique using serum from leukemic pigs, and by indirect staining technique using anti-pig leukemia antisera prepared in rabbits. Subsequent to this, these cell lines will be examined electronmicroscopically for cellular alteration or presence of foreign particles, and by staining with ferritin conjugated antiserum.

$$
\text { Inhalation Studies - W. J. Bair }
$$

Heterophile antibody-forming capacity was reexamined in rats which had inhaled $0.1-0.5 \mu \mathrm{Ci}$ of $239 \mathrm{PuO}_{2}$. From 1 week through 6 weeks after the ${ }^{239} \mathrm{PuO}_{2}$ exposure the antibody formation in the exposed groups was 25-50\% of the controls. This confirms the findings of the initial experiment reported in April.

Intraperitoneal administration of approximately $1.5 \mathrm{Ci}$ $239 \mathrm{PuO}_{2}$ did not result in a peripheral blood lymphopenia during the first month after deposition of particles. A significant amount of $239 \mathrm{PuO}_{2}$ particles was translocated back into the peritoneal cavity at 1 and 2 weeks after their deposition, with $36 \%$ of the activity in the peritoneal wash at 2 weeks. Liver activity consistently increased during this time, while spleen activity decreased. Body weights of plutonium-treated rats were significantly lower than controls during the first month. 
Co-administration of 0.3 millimole $\mathrm{Mg}^{++}$with ${ }^{239} \mathrm{PuO}_{2}$ did not result in an increased uptake of activity in the mesenteries as was observed with calcium. Administration of calcium 1 hour after deposition of $239 \mathrm{PuO}_{2}$ in the peritoneal cavity produced the same fast uptake of activity into the mesenteries as was observed when both were given simultaneously. Intraperitoneallyadministered 0.02 and 0.5 millimole of DTPA with ${ }^{23}{ }^{\mathrm{PuO}_{2}}$ particles prevented the normal loss of activity from the peritoneal washand the gain in mesenteric activity 24 hours after their injection.

The biliary excretion of ${ }^{239} \mathrm{Pu}$ after inhalation was investigated in rats. In two separate experiments bile was collected for 2 hours at $1,3,7,14$, and 38 days after ${ }^{239} \mathrm{Pu}\left(\mathrm{NO}_{3}\right)_{4}$ exposure. The 2-hour biliary excretion of $239 \mathrm{Pu}$ ranged from 0.001 to $0.045 \%$ of the total body burden of the animals. The highest values were obtained on the third and seventh day. From these studies it is evident that inhaled ${ }^{239} \mathrm{Pu}\left(\mathrm{NO}_{3}\right)_{4}$ is excreted via the bile duct into the gastrointestinal tract.

The final results of the last $\mathrm{x}$-ray experiment confirm the previous ones. Thoracic x-irradiation has an effect on neutral lipids of lung tissue and not on phospholipids. This effect lasted during the whole experiment. X-irradiated animals show a drop in neutral lipias the first day postexposure followed by an increase the second day postexposure. The fourth day the animals receiving $800 \mathrm{R}$ had more lipids than the controls (21 versus $18 \%$ ). The animals receiving $1500 \mathrm{R}$ had less neutral lipid in their lungs than the controls after the second day. The total oH-proline of lung tissue increased from the second day postexposure. The results with collagen were similar to previous experiments, with animals receiving $1500 \mathrm{R}$ showing a smaller variation than those receiving $800 \mathrm{R}$, thus making the increase in collagen during the fourth day postexposure more pronounced. Elastin increased the eightday postexposure in both $\mathrm{X}$-irradiated groups.

Rats were exposed to $239 \mathrm{PuO}_{2}$ aerosols and then randomly divided into six groups of five animals. Five groups were given 11 treatments of tryptamine, progesterone, thyroid-stimulating hormone, seratonin or prednisolone. The sixth group received only the vehicle and served as controls. All the animals were sacrificed at the 18 th day and their lungs assayed for $239 \mathrm{Pu}$. 
The progesterone group was about $20 \%$ lower than the controls. There was no significant difference between the other groups and the controls.

Excretion Rates vs. Lung Burdens in Man

- W. J. Bair/C. E. Newton, Jr.

Six beagle dogs were exposed to ${ }^{239} \mathrm{PuF}_{4}$ dust. The initial burden was estimated at 3-17 $\mu \mathrm{Ci}$. Three of the animals were treated with $0.5 \mathrm{~g}$ of DTPA, each for 5 days and then every 3 days for $1 \frac{1}{2}$ weeks. Based on whole-body counting, the DTPA treatment was effective only the first 24 hours after exposure but urinalysis is not yet complete for a more accurate assessment of this therapy. No $239 \mathrm{Pu}$ was found in the blood samples taken at 1 hour and 24 hours after exposure in any of the dogs.

Because of unavailability of cyclotron irradiation time, procurement of $237 \mathrm{pu}$ for testing as a suitable material for human studies (by the Hanford occupational Health Foundation, Inc.) remains unrealized. Theoretical excretion of plutonium in feces following inhalation of plutonium aerosols of various particle sizes was developed using the parameters of the new ICRP lung model. According to these calculations, the contribution of endogenous fecal plutonium is insignificant compared to the amount of material passing directly from lung to G.I. tract for several years after an inhalation of plutonium.

\section{Biological Systems Model Development - W. J. Bair/ G. E. Driver}

Further development on a lung model to fit the beagle data on retention of inhaled $\mathrm{PuO}_{2}$ has led to some changes in the assumptions regarding translocation of plutonium from the lung. We now have the fraction of radionuclide moving from the deep lung to lymph at $25 \%$ and the fraction from deep lung to blood at $10 \%$. The fraction from blood to bone is now 25\% and blood to liver is $70 \%$. We have chosen the fraction from liver to blood to be $90 \%$ and liver to gut as $10 \%$. Only $1 \%$ of the kidney burden gets back to the blood. The long-term model has helped to define the deep lung half-time as 725 days instead of the 360 days suggested by the ICRP. 


\section{Space vucloar Eystems studies - R. C. 'I'hompson}

$239 \mathrm{PuO}_{2}$ microspheres were fed to three pigs in amounts equivalent in mass to that fed in the earlier $238 \mathrm{PuO}_{2}$ feedings. The radiation was thus $1 / 280$ of that delivered by the $238 \mathrm{Pu}$. At necropsy on the 14 th day after administration of the microspheres there were no gross pathologic changes noted nor were any microspheres detected in the gastrointestinal tract. Data from fecal analyses are not yet available.

The solubility of four ${ }^{238} \mathrm{PuO}_{2}$ microspheres in simulated gastric juice (SGJ) was studied as a function of time. These microspheres were carefully selected for similarity in size, sphericity and smooth surface and all had been isolated after passage through the gastrointestinal tract of a pig. They were from the batch of microspheres which had been ultrasonically cleaned by Mound Laboratories. Results were quite variable, but a maximum solubility from a single particle would appear to be about $10^{-7} \mathrm{~g} / \mathrm{mm}^{2}$ surface area/liter SGJ, after $30 \mathrm{~min}-$ utes. A figure twice this high would seem to be a maximum for 48 hours exposure.

Four of six dogs that inhaled crushed ${ }^{239} \mathrm{PuO}_{2}$ microspheres have died. Hemoconcentration, change in respiration, minute volume, partial pressure of oxygen and carbon dioxide and the $\mathrm{pH}$ of blood have all shown deviation from normal in the dogs exposed. The first to die, 50 days after exposure, had $96.8 \%$ of $238 \mathrm{Pu}$ in lung and $2.14 \%$ in lymph nodes. Total body burden was $74 \mu \mathrm{Ci}$.

Three beagle dogs that had retained lung burdens of 50-75 $\mu \mathrm{Ci}$ of $238 \mathrm{PuO}_{2}$ for 2 months were examined for antibody-forming ability. No heterophile antibodies were detected in serum dilutions beyond 1:32 while control dogs still had detectable heterophile antibodies in serum dilutions up to $1: 256$.

Uranium Ore Inhalation, Radiochemical Studies - R. W. Perkins

The determination of uranium in certain biological materials, particularly fecal samples, has been difficult because of the large amounts of salts present. To expedite this analysis, neutron activation is being investigated to see if uranium can be better determined by direct counting of its fission product daughters following neutron activation of the biological samples. 


\section{Plutonium-Americium Studies - R. W. Perkins}

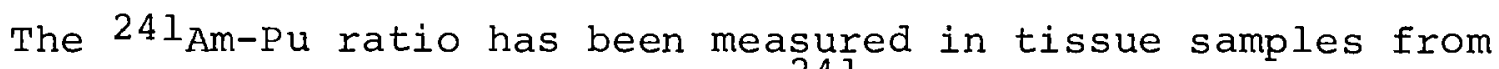
dogs which were exposed to $\mathrm{Pu}$. The $24 \mathrm{l}_{\mathrm{Am}-\mathrm{Pu} \text { concentrations are }}$ being measured by direct counting on the Si(Li) diode and on some they are also being measured by chemical separation and alpha energy analysis. The initial results are good only to $\pm 10 \%$ but it is expected that \pm 2 to $3 \%$ values can ultimately be obtained. The data are not yet sufficient to determine if significant disequilibrium occurs between the lung where the Pu is initially deposited and the lymph node and liver, where it later accumulates.

\section{MOLECULAR AND CELLULAR LEVEL STUDIES}

\section{Cellular Regulatory Mechanisms - W. H. Matchett}

Continuing our investigation of the role of tryptophanylsRNA synthetase in the regulation of tryptophan synthetase in Neurospora, we have tested several indole derivatives for their capacity to alter the charging of the tryptophan-sRNA. These experiments were designed to provide evidence for or against the proposal that indole glycerol phosphate, a precursory of tryptophan, is involved in the regulation of tryptophan biosynthesis. The indole derivatives were added to the charging mixture at a concentration of $2.5 \mu$ moles $/ \mathrm{ml}$. Indole inhibited tryptophan charging, 14\%; indole lactate, 31\%; indole acetate, 53\%; indole propionate, 78\%; indole pyruvate, 83\%, and indolebutyrate, $90 \%$. At a concentration of 0.5 umole/ml, only indole propionate and pyruvate were effective inhibitors. Apparently, those derivatives with three or four carbon atoms in the side chain are more effective inhibitors than indole or indole acetic acid. This generalization, however, does not hold for indole lactate.

It should be pointed out that although the herbicide 3-amino 1-2-4 triazole ( $3 \mathrm{AT}$ ) causes derepression of tryptophan synthetase in whole cells, it has no effect on the tryptophan charging reaction at concentrations from 0.05 to $1 \mu \mathrm{mole} / \mathrm{ml}$. These data confirm, in part, our original contention that derepression of tryptophan synthetase by $3 A T$ is a result of $3 A T-i n d u c e d$ accumulation of imidazoleglycerol phosphate which mimics the inhibitory effects observed for indole derivatives. 
It was previously shown that high intracellular pools of tryptophan, formed from externally supplied tryptophan, inhibit the activity of the tryptophan transport system in Neurospora. Recent results have shown that intracellular pools of tryptophan formed from exogenously supplied indole also inhibit the rate of tryptophan transport. This provides additional support for the contention that tryptophan transport is regulated by the intracellular pool of tryptophan and is only secondarily related to the extracellular concentration of tryptophan.

Preliminary results suggest that the tryptophan transport system in Neurospora can be released from the membrane by controlled osmotic shock in sucrose-containing medium. This may provide a technique which will permit the isolation of the tryptophan transport system.

Characterization of Radiation-Induced Free Radical Reactions in Aqueous Systems - D. R. Kalkwarf

Investigation of the intermediates formed in the radiationinduced oxidation of p-aminobenzoic acid in aqueous solution was continued utilizing pulsed electron irradiation, long-term gamma irradiation and electron spin resonance spectrometry. This component of the folic-acid vitamins reacts extremely rapidly with hydroxyl radicals, the rate constant being $4.9 \times 10^{9} \mathrm{M}^{-1} \mathrm{sec}^{-1}$ as measured by competition kinetics with erioglaucine. It would thus be a very susceptible site for the initiation of radiobiological damage. Kinetic spectroscopy of aqueous p-aminobenozic acid following $I \mu$ sec pulses of $3 \mathrm{MeV}$ electrons from the Varian accelerator at ohio state University confirmed this rapid attack by showing immediate buildup of a species absorbing at $450 \mathrm{~nm}$. This transient species decayed rapidly by a pseudo first-order process suggesting reaction with dissolved oxygen; and the rate constant calculated

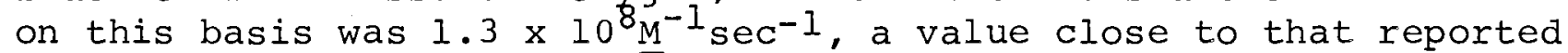
for the reaction of the hydroxycyclohexadienyl radical, formed during aqueous benzere solution raidolysis, with molecular oxygen.

Efforts to detect ESR spectra of radicals derived from radiolysis of p-aminobenzoic acid solutions in an irradiated flow system have been unsuccessful as yet and so further investigation of spectra obtained during the reactions of this compound with other oxidants was pursued. A multi-lined ESR spectrum was obtained following rapid mixing of p-aminobenzoic acid with titanous sulfate and hydrogen peroxide, a mixture known to generate hydroxyl radicals as intermediates. The spectrum was complex, being composed of at least three superimposed components: a broad 60 gauss singlet, a 2 gauss singlet presumably due to the hydroxyl radical and an 240 line spectrum with spacings 1.6 gauss apart. Comparison of this ESR spectrum with that for the arylammonium radical-cation formed with p-aminobenzoic acid is 
oxidized with ceric sulfate failed to show any similarity. Further efforts will be made to identify the structures of these new radicals.

Final products obtained after prolonged irradiation of $p$ aminobenzoic acid were also investigated to obtain clues for determining the mechanism of the radiation-induced reaction. Reports in the literature conflict with both 3-hydroxy-4aminobenzoic acid and p-nitrobenzoic acid being proposed as the principal product formed in air-saturated systems. Examination of products formed under various conditions by thin-layer chromatography revealed a high sensitivity of the reaction to both $\mathrm{pH}$ and molecular oxygen but no p-nitrobenzoic acid was found under any conditions.

\section{ENVIRONMENTAL RADIATION STUDIES}

\section{Terrestrial Ecology - R. E. Nakatani}

The above ground parts of winter annuals living on a 20year-old abandoned agricultural field were harvested for the fifth consecutive year. The total dry weight averaged 276 grams per square meter. This is the highest yield yet reported. The high yield is attributed to abundant autumn precipitation during the time of seed germination and abundant late spring precipitation which extended the growing season by several weeks. Eighty-three percent of the plant biomass was contributed by cheatgrass and $17 \%$ by Jim Hill Mustard.

As in previous years, the only plants observed growing on the field were weedy plants of European origin. The harvested plants are being examined for their radionuclide content.

Trapping was resumed on the Rattlesnake Springs study area following a brief period of inactivity. Over 1,000 trap-nights were logged until eventually over $90 \%$ of the animals trapped were recaptures. Trapping success dropped markedly to about 55\% in mid-June, at about the same time as the luxuriant crop of cheatgrass ripened and the hot weather set in. Success improved, however, with the influx of juvenile Perognathus parvus that have just been weaned and are now foraging for themselves. 
A group of 90 Peromyscus maniculatus were irradiated at doses which affected 5-95\% mortality in a previous experiment. The additional data at these critical doses will increase the sample sizes to 25 animals, which should improve the statistical problems. A shipment of 185 Perognathus longimembris were received from southern California. As soon as they have had a chance to acclimate to our laboratory they will be included in the radiation lethality studies. The "least pocket mouse" had the highest $\mathrm{LD}_{50 / 30}$ value $(1530 \mathrm{R})$ reported for any mammal, and we intend to check its response to radiation under our experimental conditions, because the local pocket mouse, Perognathus parvus, has a much lower resistance (862 R) to acute radiation.

$$
\text { Columbia River Ecology - R. E. Nakatani }
$$

High water has precluded all but plankton sampling in the river.

Shoreline discharges of heated reactor cooling water attract large numbers of carp (Cyprinus carpio) during the winter months. High temperature water and dissolved substances from dense blue-green algal growths are suggested as possible attractants. The area in which observations were made is immediately downstream from the 100-D Reactor Area. At this point hot groundwater derived from the cooling:water retention basin emerges at about the high water mark and flows in several small streams to the main river. This pattern of ground water seepage is apparent at all reactor areas with the exception of $100-\mathrm{N}$.

Congregation of fish in thermal discharges is a commonly reported phenomenon. 'Most investigators have thought that warm water per se is the attractant. A second possibility is that carp are attracted to the discharges of organic matter dissolved in the water. Heated discharges often produce dense mats of blue-green algae which are known to produce extracellular organic matter. These mats were a conspicuous feature of the seepage streams below 100-D.

\section{Earth Sciences - W. A. Haney}

An area of the Rattlesnake Hills centering on Snively Ranch was studied. It lies northeast of the Rattlesnake No. 1 
well where the Rattlesnake Hills turn from a northwest to west trend. Early workers there mapped a large thrust fault; later workers (1953) mapped a huge landslide that covers 13.5 square miles. If the slide is that large, its relationships to the Rattlesnake Hills anticline and to possible faults and earthquakes need to be known.

Two major anticlinal axes were traced into the area, one from the west, the other from the southeast. The latter axis passes to the north of the one from the west and dies out on the lower slopes of the hills. A plateau, centering in the "slide" area, slopes gently northward between the two anticlines and includes a small intervening syncline. Alluvial fans, colluvium, irregular topography and small slides suggest a large slide. That it is not present is demonstrated by (1) continuity of the northernmost anticline and adjacent syncline across the "slide," (2) generally gentle dips, (3) cantinuity of specific basalt flows and sedimentary interbeds, and (4) lack of rotated blocks, abundant breccia and true landslide hummocky topography in the main part of the area. Slides appear limited largely to the steeply dipping north limb of the northernmost anticline. The thrust fault, evidently postulated to explain the offset of the believed single anticline, does not exist because the two anticlinal axes cross the "fault" without offset.

Low angle dips to the north form a nearly symmetrical Rattlesnake Hills in contrast to the marked asymmetry to west and southeast. The anticlinal axial plane at the Rattlesnake No. 1 Well accordingly is nearly vertical and the well did not enter the north limb of the anticline. Logs obtained from the well in 1958 and 1967 suggest flat-lying basalt flows that now are confirmed.

Samples of coal and wood fragments found at the 3240-3340 foot depth in the Rattlesnake well were taken to Denver to be analyzed by the U. S. Geological Survey. Initial examination revealed the probable presence of pollen in a satisfactory state of preservation for use in identifying the plant genera present during the time of extrusion of the basalt flows. It should be possible with further detailed study to reconstruct the paleoecology during the time of the flows.

More general discussions with the USGS staff on the use of paleobotany in general and palynology in particular as a tool in deciphering the stratigraphy of the Columbia Basin were most 
encouraging. Their experience has shown it possible to recover useful spore and pollen data in practically every environment except one where a strong oxidizing state existed for any length of time. Samples of the Ringold Formation and Touchet sediments were also examined and the consensus was that they should readily yield spore and pollen data when properly treated.

Additional samples of coal cuttings at selected depths in the Rattlesnake well will be segregated for analysis if the samples now in preparation prove to be satisfactory.

Capabilities were added to the computer program FUNEVAL that converts the canonical form into an equivalent polynomial series for surface equations. Since the canonical form is composed of a cumbersome number of terms which are scaled differently, increased efficiency of computer programs that utilize surface equations as input is realized when the surface is described by polynomial series. The magnitude of the increased efficiency is considerable in that the programs using these equations require first and second order derivatives.

\section{ATMOSPHERIC RADIOACTIVITY AND FALLOUT}

Radioisotopes as Particles and Volatiles - L. C. Schwendiman

Turbulent Deposition in Vertical Tubes - G. A. Sehmel

The difference in the deposition of particles in two, in-series, apparently identical, $12 \mathrm{ft}$ long tubes has at times been highly significant. The source of the difference could not be traced unequivocally to subtle differences in tube surface or differences in quality of particles since possible differences in these parameters may have been occurring simultaneously in the experiments. Some experiments were conducted to help establish the sensitivity of the deposition to variations in tube surface roughness within the range of roughness of "as received" tubing. No deliberate effort was made to increase tube roughness but tubes were selected by visual observation which were relatively rough or smooth-walled. Efforts to quantitatively measure the surface roughness were unsuccessful due to the softness of the aluminum for the profilometer available. These selected tubes were used in parallel; 
through each tube was passed monodispersed particles from the aerosol settling chamber during the experiments.

For $5 \mu$ particles and non-entraining flow conditions, deposition was virtually identical in two random 12 ft lengths of 1.125 in. ID tubing.

Tubes were chosen which appeared to be relatively rougher than others. Two 12-ft tubes were assembled from 6-ft lengths; one "rough" and one "smooth." Sixteen-micron particles were drawn through these assemblies at a Re number of 23,900, a flow known to cause significant re-entrainment. The assemblies showed the same deposition suggesting that, if surface effects were important, they were equal in this run. The difference among the 6-ft segments could not be related to the rough or smooth tubes.

In another experiment, the deposition of $16 \mu$ particles in two 12-ft lengths of tubing, one smooth, one rough, was measured for a $\operatorname{Re}$ of 23,900. The rough tube showed a net deposition of $20 \%$ and the smooth, 2\%. The behavior is not yet explained. Previous experiments had strongly suggested that the range of surface quality of the as-received tubing was not wide enough to cause such large differences in deposition. Since flow conditions and particle size were selected for which re-entrainment does occur, one hypothesis is that re-entrainment itself may be significantly affected by surface roughness, the smoother surface causing enhanced reentrainment, and that the low net deposition may have resulted from a very smooth surface peculiar to this particular tube.

Deposition was markedly enhanced by swirling flow. Spiral steel ribbons with a pitch of five inches were inserted in the entrance $36 \mathrm{in.} \mathrm{of} \mathrm{a} \mathrm{tube.} \mathrm{Deposition} \mathrm{of} 5 \mu$ particles was $20 \%$ in the downstream $30 \mathrm{in.} A$ Re of 23,900 was used. In the absence of the swirl generator, about $2 \%$ was deposited.

Radioactive Fallout Rates and Mechanisms - R. W. Perkins

Most of the assembly work was completed on the Noble Gas Atmospheric Diffusion Monitoring system and work is in progress for the field installation. Ground sampling positions on the first two arcs at 200 and 800 meters are being established. Three towers on each arc, at the center and the outer edges, will be equipped with detectors.

The annual spring increase in radioactivity in air confirmed the 11.7 month stratospheric mean residence time for fallout debris as determined from ground level measurements over the past 4 years. 
Radioanalytical Procedures Development - R. W. Perkins

It was mentioned in the recent conference on Activation Analysis in the Life Sciences at Amsterdam that an $\mathrm{Sb}_{2} \mathrm{O}_{5}$ column would selectively remove radiosodium from acid solutions, allowing other radioelements to pass through. Measurements in our laboratory have shown that with chemically pure $\mathrm{Sb}_{20} 5$, the sodium is not retained; however, on using $\mathrm{Sb}_{2} \mathrm{O}_{5}$ manufactured by the Carlo Ebber Chemical Co. of Milano, Italy, quantitative retention of radiosodium from $6 \underline{\mathrm{N}} \mathrm{HCl}$ or $12 \underline{\mathrm{N}} \mathrm{H}_{2} \mathrm{SO}_{4}$ was achieved. Preliminary measurements indicate that othe $\bar{r}$ radionuclides are not held by the $\mathrm{Sb}_{2} \mathrm{O}_{5}$ column. This technique will be further developed to determine the feasibility of its use in removing ${ }^{24} \mathrm{Na}$ from neutron-activated biological and environmental samples.

In an experiment to produce enriched $40_{\mathrm{K}}$ by neutron activation of natural potassium, it was shown that essentially all of the contaminating radionuclides produced from impurities in the potassium could be removed by passing a neutral solution of the irradiated material through an anion column in the carbonate-hydroxide-sulfide form. The only radionuclides passing through this column in addition to those of potassium were isotopes of sodium and rubidium. This technique thus appears suitable for removal of all the non-alkali metal radionuclides from radiated potassium.

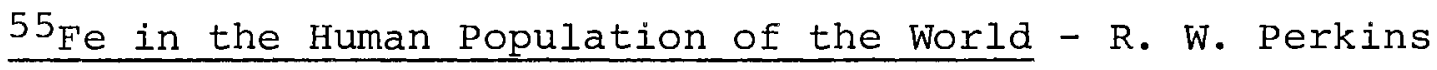

${ }^{55} \mathrm{Fe}$ concentrations in local food products from the state of Washington are being compared with those observed in late 1964 when the $55 \mathrm{Fe}$ work was started. Of the 6 types of meats which have been studied, the present concentrations are about half of those observed $2 \frac{1}{2}$ years ago and thus appear to be decreasing at about the half-life of ${ }^{55} \mathrm{Fe}$.

Samples of blood from several more mother-fetus pairs from Alaska have shown that the specific activity of iron in each pair is about constant. A sampling program will be conducted next month to obtain blood and hair samples from individual Alaskan Eskimos to determine the relationship between the ${ }^{55} \mathrm{Fe}$ in the hair and that in their body. This will provide information on how precisely a person's body burden of $55 \mathrm{Fe}$ can be estimated from 55Fe measurements in his hair. This sampling program will also include the collection of the salmon from the west coast of Alaska which are high in 55Fe and various 
samples of vegetation and native foods which contribute to the $55 \mathrm{Fe}$ and other radionuclides observed in the Alaskan Eskimos.

\section{Transport and Diffusion}

Wake Studies - W. T. Hinds

Analysis of the time history of trace concentration at a point has shown an approximate power law dependence of the variance of concentration on smoothing interval. This led to a mathematical investigation of the variance of a smoothed random variable. The resulting equation is quite general, applying to any stationary continuous random function of a single independent variable.

If $\sigma^{2}$ is the variance of the unsmoothed variable, $\sigma_{s}^{2}$ is the variance of the smoothed variable, $t$ is the interval of smoothing, $P(x)$ is the autocovariance of the unsmoothed variable at $\operatorname{lag} x$ and $R_{S}(x)$ is $P(x) / \sigma_{S}^{2}$, then

$$
\frac{d \sigma_{S}^{2}}{\sigma_{S}^{2}}=2\left\{R_{S}(t / 2)-1\right\} \frac{d t}{t}
$$

Since $R(t / 2)=P(T / 2) / O^{2}$ is the autocorrelation of the unsmoothed function, $R_{S}(t / 2)$ is approximately an autocorrelation. Assuming the simplest plausible form for $R_{S}(t / 2)$ to be linear so that $2\left\{\mathrm{R}_{\mathrm{S}}(\mathrm{t} / 2)-1\right\}=\mathrm{b}+\mathrm{kt}$, the equation can be integrated from $t_{0}$ to $t$ to yield

$$
\frac{\sigma_{S}^{2}}{\sigma_{S, 0}^{2}}=\left(\frac{t}{t_{0}}\right)^{b} e^{k\left(t-t_{0}\right)}
$$

This result indicates, by virtue of the exponential term, that the drop off in smoothed variance with increased $t$ is greater than for a simple power function and is in good agreement with the data. A rate of drop off exceeding the simple power law was found in other investigator's data, but neither theoretical explanation nor discussion was provided. It may be noted that the functional form chosen for $R_{S}(t / 2)$ is not critical since $\sigma_{\mathbf{S}}^{2} / \sigma_{\mathbf{s}, 0}^{2}$ depends upon the integral of the chosen form, thus smoothing out much of the error involved. 
Diffusion Test Series 4-D - P. W. Nickola and M. A. Wolf

Seven tests, similar to one previously reported, have been conducted to provide elevated and surface definition of the instantaneous properties of a continuous ground source of tracer. To accomplish this, consecutive cross-wind traverses of the plume were made with a vehicle-mounted real time sampler and with the airborne real time sampler along the 3200 meter arc on the Hanford diffusion grid. Time integrated tracer concentrations were measured on the 800 and 3200 meter arcs and on the five towers of the 3200 meter arc. Meteorological data were recorded concurrently at the source and in the aircraft.

Detection of the tracer was made at 25,600 meters for one test but quantitative measurements were obtained up to only half that distance. At 3200 meters good measurements were obtained both on the ground and in the air for most tests. Initial examination of the records indicates that variations in the plume geometry were described quite well by the real time samplers. The instantaneous properties of the continuous plume emphasize the local influences which perturb the mean flow while the relationship of the instantaneous properties to the time-averaged properties provide additional insight into the nature of the instantaneous generated puff. Data reduction and analysis for this test series was started.

\section{Precipitation Scavenging Studies}

Laboratory Studies - D. I. Hagen

A point-to-plane electrostatic precipitator was fabricated for the purpose of obtaining non-biased samples of sub-micron particles for routine particle size analysis. The particles are collected directly on electron microscope grids to minimize pre-examination handling. Although previous investigations by others indicate that the precipitator collects essentially nonbiased samples with a mass efficiency of greater than $60 \%$ for particles in the approximate range of 0.1 to $10 \mu$, preliminary results indicate that silver iodide particles having sizes smaller than 0.05 micron may not be collected by this instrument. A thermal precipitator is on loan for particle size analysis and will be used in the evaluation of the electrostatic precipitator for the smaller particle sizes. 
A chamber to study the removal of gases and particulates by monodisperse water droplets on a laboratory scale is in the fabrication stage. The particulates employed may be either polydisperse or monodisperse. Provisions will be made to charge the particles and the water droplets electrically. An instrument is available for measurement of droplet charges and for determination of their fall velocity. Temperature and humidity control of the chamber together with control of the $\mathrm{pH}$ and chemical composition of the water droplets will further simulate natural rain and its environment. The chemical properties of the droplet are expected to be a significant factor in washout, particularly of gases. This modeling study with controlled parameters should prove to be an effective approach to the experimental investigation of the physical mechanism involved in washout. Initially, the particulate employed will be zinc sulfide $(\mathrm{znS})$ in order that established methods for detection and analysis can be used and so that results of numerous previous studies using $\mathrm{ZnS}$ can be used to evaluate the performance of the chamber.

Theoretical studies - W. G. N. Slinn

A theoretical investigation of precipitation scavenging of submicron size particles was started. In the particle approach that is used, both electrical and Brownian effects are included. The inertia of the particle is negligible. The solution to the resulting (Smoluchouski) equation yields that the probable location of the particle is "diffused" about a point on a trajectory governed by the flow field about the liquid drop and the ratio of the coulomb force to stoke's drag force on the particle. During the coming months the trajectories will be integrated numerically and the collection efficiency evaluated.

\section{MARINE SCIENCES}

\section{Physical Chemistry of Ocean Solutions - R. W. Perkins}

It has been shown through laboratory experiments that certain trace elements in sea water are depleted through attachment to polyethylene or glass surfaces. Our standard method for sea water sample collection has, therefore, been revised to include addition of sufficient doubly distilled concentrated $\mathrm{HCl}$ to a polyethylene bottle to result in a $0.1 \mathrm{M} \mathrm{HCl}$ solution when filled 
with sea water. The trace elements $\mathrm{Cs}, \mathrm{U}, \mathrm{Sb}, \mathrm{Br}, \mathrm{Co}$ and $\mathrm{Zn}$ are not significantly depleted even from neutral solutions. Measurements of the Cs, U, Sb, Br between Newport, Oregon, and Hawaii show very constant concentrations whereas $\mathrm{zn}$ varies by about twofold and co by about tenfold.

Joint oceanographic expeditions with the oregon State University Department of oceanography and the University of Miami Marine Laboratory are being conducted during June and July. In these studies, samples of ocean water and marine organisms from various depths and locations will be analyzed for radionuclides and trace elements. In addition, air samples will be taken to provide information on sea-air interface exchange processes. The sampling program with oregon State University will take place June 23 to June 30 while the program with University of Miami will begin after July 6 and will cover an ocean area between Miami and Dakar, Africa.

\section{RADIOLOGICAL AND HEALTH PHYSICS}

\section{Radiation Dosimetry - W. E. Wilson}

Following repairs in the calibration electronics, the absorbed dose calorimeter was recalibrated. Four repeat measurements of the dose rate from a standard ${ }^{60} \mathrm{Co}$ source all agreed to within 2\%. This good precision was not matched by the initial accuracy calculations since we discovered that the standard source carried an incorrect calibration number for the activity. When our measurements were compared with the correct standard dose rate, agreement appeared to be very good even though not all corrections had been made to the data.

The grid-walled proportional counter to be used in determining the magnitude of the effect due to wall-scattered low energy electrons in micro-dosimetry measurements now appears to be functioning adequately for these measurements. The electrical breakdown which has prevented operation at the necessary gas gain was eliminated by redesigning the insulator between the field tube and the anode. Gains as high as $2 \times 10^{3}$ have been obtained. The noise level when operating at this gain can still be kept below 1000 rms electrons. The low noise figure is made possible by using an FET preamplifier although considerable difficulty was experienced in applying the detector bias voltage $(\sim 1000 \mathrm{v})$ without destroying the FET. Attempts 
to use RC filters having time constants of several seconds failed. The problem was solved by adding a low capacitance reed switch to the circuit. This switch can be activated by an external magnet and it shorts the FET input to ground during bias voltage changes.

Preliminary data were obtained for ${ }^{14} \mathrm{C}$ beta particles in solid-wall cavities having dimensions of about $0.7 \mu$ and $3.5 \mu$. Events a large as $5 \mathrm{keV} / \mu$ were observed. This experiment was originally planned to investigate the gas-solid interface of ethylene-polyethylene using ${ }^{14} \mathrm{C}$ beta particles. Since ${ }^{14} \mathrm{C}$ labeled polyethylene seems to be unavailable, methyl methacrylate and a mixture of carbon dioxide and ethylene which has the same stopping power over the energy range of interest will be used.

The 4 in. diameter spherical copper counter was set up in a glass bell jar without Lucite components to eliminate gas contamination problems. Measurements of gain as a function of track angle were made. With flat field shaping electrodes, gain is highest for tracks at $50^{\circ}$ to the collecting wire, then it drops $7 \%$ at $80^{\circ}$ and $26 \%$ at $20^{\circ}$. Sloping the field-shaping electrodes back from the wire may improve the gain at small angles but this has not yet been tested in a contamination-free counter.

Calculations were made to determine the approximate dimensions of a spherical counter using a small sphere on the edge as the collecting electrode. The electric field would be shaped by dividing the spherical wall into annular rings of conducting material, each at the potential that would exist in free space at that point with respect to the collecting sphere. The width of these rings was calculated so that the potential on the wall was never more than $30 \%$ different than it would be in free space. For a $10 \mathrm{~cm}$ diameter sphere, the ring with its plane $3 \mathrm{~mm}$ from the collecting sphere is only $0.3 \mathrm{~mm}$ wide. This is already impracticably thin and rings much thinner would be needed to maintain the spherical field around the collecting electrode. 


\section{RADIATION INSTRUMENTS}

Radiation Detection and Measurement Instruments - W. G. Spear

Completion of environmental field testing prepared the experimental mixed-field, neutron-gamma monitoring system for use in the field under operating conditions. Instrumentation operation proved to be satisfactory over a temperature range from 0 to $100^{\circ} \mathrm{F}$ following a high temperature conditioning at $125^{\circ} \mathrm{F}$. A minor noise problem, resulting from moisture condensation at low temperatures, appears fully capable of solution through use of a desiccant near the gamma detector, thus avoiding need for a heater which increased total power requirements.

Purchase of a special detecting system, comprising a cooled Si(Li) detector with a cooled, first stage, solid state preamplifier, greatly expands the solid state $\mathrm{X}$-ray and gamma spectroscopy capability. To reduce absorption of the lowenergy photons through the entrance window and increase detector efficiency, the stainless steel shroud is fitted with an aluminized Mylar window. System tests were initiated. The modified "L" bend cryostat developed a leak in one flange groove and, being uneconomical to repair, it will be replaced with a portable satellite Dewar, capable of orientation in any direction.

Fabrication of the printed circuit cards and modules for the experimental tidal volume air monitoring system progressed to completion and assembly of the system is proceeding on schedule. Further evaluation of the transducers to be used has been delayed until the assembly is completed.

Continued cooperative efforts with Biology in establishing an experimental surface tension measuring instrument experienced delays due to lack of appropriate components for the $\mathrm{X}-\mathrm{Y}$ recorder. This project will be expedited upon arrival of the required components as the developmental aspects are essentially completed.

Replacement of the beryllium window for the solid state detector spectroscopy system with a Mylar window provided considerably more efficient $\mathrm{X}-\mathrm{ray} / \mathrm{alpha}$ ratio studies. In addition to the new shroud, source holders and an alpha counting chamber were completed. From the available solid state detector diodes, one with a resolution of $0.5 \%$ at $5.48 \mathrm{MeV}$ was 
selected for alpha measurements. The source being used is one deposited upon a platinum disk; however, due to the presence of salts with the plutonium, the resolution proved to be less than with previous sources. Measurements made with the X-ray/alpha combined proportional and scintillation system improved the statistical knowledge for such studies. The following table describes the results of measurements made with four known, different sources.

Measurement of $\mathrm{X}$-ray/alpha and Gamma/alpha

\section{Ratios for known Sources}

Source

$238 \mathrm{Pu}$

$239 \mathrm{Pu}$

$239 \mathrm{Pu}$

$240 \mathrm{Pu}$ $\underline{x-r a y / A l p h a}$

$0.112 \pm 0.001$
$0.0485 \pm 0.0004$
$0.0737 \pm 0.0007$
$0.109 \pm 0.0005$

Gamma/Alpha

$$
\begin{aligned}
& 5 \times 10^{-4} \\
& 6.03 \times 10^{-4} \\
& 0.0191 \pm 0.0006 \\
& (2.32 \pm 0.05) \times 10^{-3}
\end{aligned}
$$

In addition to these measurements, the mathematical relationships required to predict the biological hazard of a given material have been formulated and used to evaluate some known sources.

Preliminary experimental evaluation continued on the surface-contoured diode ${ }^{55} \mathrm{Fe} x$-ray counting unit recently received. The measured intrinsic $x$-ray efficiency at 0.01 volt below high voltage breakdown approached 25\%, as compared with a value of $38 \%$ stipulated by the supplier. Reasons for this discrepancy have not, as yet, been determined. At 0.1 volt below oscillation, the efficiency was approximately 18\%. Further studies are planned using these diodes as $239 \mathrm{pu}$ wound detectors as soon as the experimental probe assembly can be obtained.

The comprehensive temperature effects evaluation program progressed for the improved experimental animal physiological function data transmitter. In the combined respirationenvironmental temperature channel, deviation from linearity of the temperature versus frequency curve is only $1.4 \%$ at the upper limit $\left(60^{\circ} \mathrm{C}\right)$ and $0.8 \%$ at $0^{\circ} \mathrm{C}$. Utilization of a special temperature-sensing element provided a compensating positive temperature coefficient. Drift in the power supply voltages caused by temperature will be reduced with revision of the regulators to 
include only one reference cell. Frequency deviation in the blood pressure channel proved to be less than.0.44\% over the entire temperature range of interest.

\section{Radiological Chemistry - R. W. Perkins}

An improved method of neutron activation of agricultural products was developed which permits the direct counting of short and long-lived radionuclides on the same sample. Normally the amounts of ${ }^{24} \mathrm{Na},{ }^{56} \mathrm{Mn},{ }^{40} \mathrm{~K},{ }^{82} \mathrm{Br},{ }^{64} \mathrm{Cu}$ are extremely high compared with the longer-lived radionuclides. By irradiating a sample for two hours, then allowing it to decay for a week or more and then reirradiating it for one minute, it is possible to determine ${ }^{24} \mathrm{Na},{ }^{56} \mathrm{Mn}, 40_{\mathrm{K}}, 82 \mathrm{Br}$ and ${ }^{64} \mathrm{Cu}$ by direct counting. On allowing the sample to decay for one week the same sample can be directly counted for the long-lived radionuclides. This technique has the advantage that all isotope measurements are made on the same sample. The NBS standard rock samples G-1 and W-1 were analyzed for cobalt and scandium by neutron activation and direct instrumental counting techniques and found to agree within \pm 10 o of the average literature values reported by other investigators.

Following neutron activation of fish muscle samples, it was demónstrated that the 9 trace elements Hg, Se, P, Br, Cs, $\mathrm{Sc}, \mathrm{Rb}, \mathrm{Fe}$ and $\mathrm{Co}$ can be determined from a direct count on the $\mathrm{Ge}(\mathrm{Li})$ diode. This technique will be applied in various ecological studies.

A calibration curve providing efficiency versus energy for the 20 cubic centimeter germanium detector is being prepared. The absolute efficiency at $810 \mathrm{keV}$ is about $0.4 \%$ and drops to $0.16 \%$ at $1830 \mathrm{keV}$. When completely defined between 0 and $3 \mathrm{MeV}$, this calibration curve will allow the quantitative analysis of gamma ray spectra recorded by the diode. 


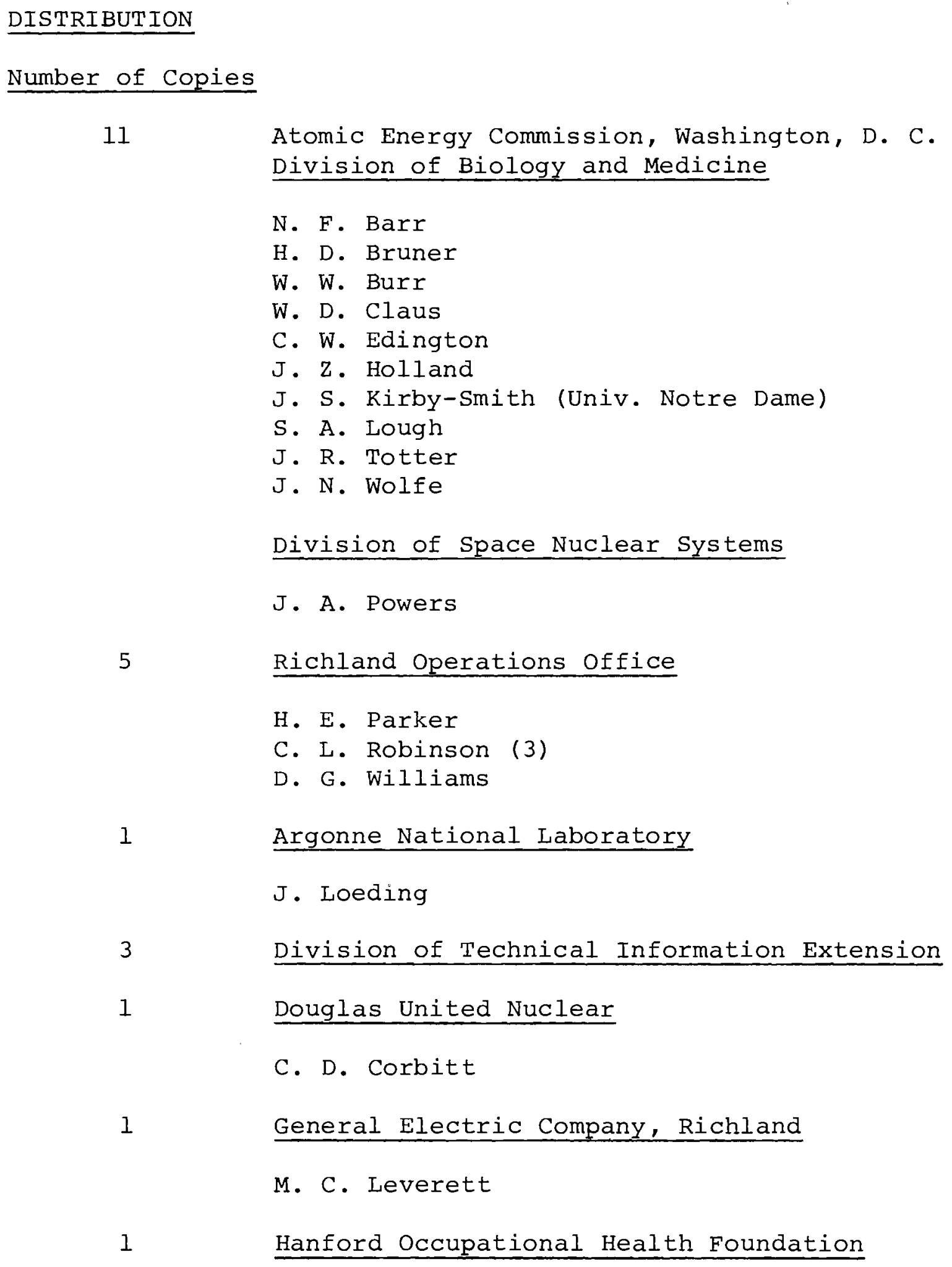

General Electric Company, Richland

M. C. Leverett 
1

65
Isochem

R. E. Tomlinson

Battelle-Northwest

F. W. Albaugh

W. J. Bair (2)

C. A. Bennett

J. J. Cadwell

W. J. Clarke (2)

F. G. Dawson

D. R. de Halas

R. F. Dickerson

W. I. Dotson

C. E. Elderkin

S. L. Fawcett

J. J. Fuquay

R. F. Foster

W. A. Haney

H. Harty

J. F. Honstead

F. P. Hungate

R. L. Junkins

D. R. Kalkwarf

A. R. Keene

H. A. Kornberg

H. V. Larson

W. H. Matchett

R. E. Nakatani (3)

C. E. Newton, Jr.

J. M. Nielsen

R. F. Palmer (2)

J. L. Palotay (2)

H. M. Parker

R. S. Paul (3)

D. W. Pearce

R. W. Perkins

E. H. Phinney

W. D. Richmond

W. C. Roesch

P. T. Santilli 
L. C. Schmid

L. C. Schwendiman

C. L. Simpson

R. J. Sorenson

W. G. Spear

M. F. Sullivan (2)

R. C. Thompson

C. R. Tipton, Jr.

C. M. Unruh

E. E. Voiland

W. E. Wilson

R. J. Wood

D. C. Worlton

Patent Section (2)

Technical Information Files

Technical Publications 